\title{
Vacunas anti-pertussis: acelular versus celular. ¿Acaso un regreso al pasado?
}

\author{
José Cofré
}

\section{Pertussis vaccines: acellular versus whole cell. Perhaps a return to the past?}

The resurgence of pertussis in the world and in our country has questioned the effectiveness of cellular and acellular vaccines. The reason why pertussis has not been controlled or eliminated after 70 years of implementation of the vaccination is probably multifactorial. This article, on the basis of questions and answers, describes the benefits and limitations of both cellular and acellular vaccines and suggests new strategies of vaccination in childhood. It is a fact that the currently applied vaccination does not eliminate the circulation of Bordetella pertussis in the community. Perhaps the introduction of vaccines with live B. pertussis, inhalation, will be able to eliminate the disease around the world.

Key words: Bordetella pertussis, pertussis, cellular pertussis vaccine, acellular pertussis vaccine.

Palabras clave: Bordetella pertussis, coqueluche, vacuna pertussis celular, vacuna pertussis acelular.

\section{¿De dónde nace la denominación de celular y acelular de una vacuna anti-pertussis?}

L as vacunas elaboradas con antígenos purificados, seleccionados porque representan factores de virulencia: pertusinógeno (o toxina pertussis$\mathrm{TP}$ ), hemaglutinina filamentosa (HF), pertactina (PRN) y fimbrias (FIM), que son capaces de estimular una respuesta inmune específica, llevaron a acuñar el término de "acelular" en contraposición de las antiguas vacunas que se preparaban con bacterias íntegras y muertas, que pasaron a ser identificadas bajo el término de "celulares".

\section{¿Cuál es la razón del desarrollo de vacunas acelulares anti-pertussis?}

Desde remotos tiempos, década del 40' se reconoció que las vacunas conteniendo Bordetella pertussis íntegra causaban alguna de las siguientes reacciones adversas locales en el sitio de inoculación (dolor intenso, eritema, celulitis aséptica) y/o fenómenos sistémicos (fiebre, llanto persistente, convulsiones, síndrome de hipotoníahipo-respuesta) en aproximadamente un cuarto a un tercio de los individuos vacunados. Incluso se temió que con su administración a edades sobre 7 años estas reacciones fuesen más frecuentes o más graves. Mucho se debatió también en los 70' un eventual efecto neurotóxico y daño neurológico irreversible secundario a su inoculación, lo que no pudo ser confirmado; el Instituto de Medicina de los Estados Unidos de América estudió este punto con detenimiento y descartó la generación de daño neurológico irreversible atribuible a la vacuna, en aquel entonces denominada DPT (vacuna Triple en nues- tro medio). Tal era el escenario de reacciones adversas descritas para el componente pertussis de la vacuna triple en esa década, que países como Japón, Suecia y Gran Bretaña la retiraron de sus programas de vacunación. Investigadores japoneses se abocaron entonces, a buscar componentes de la Bordetella capaces de estimular una respuesta inmune específica y a establecer aquellos determinantes de los efectos adversos de la vacuna con células enteras logrando identificar y purificar aquellos factores de virulencia y antigénicos antes mencionados; fue el origen de la elaboración y posterior introducción de vacunas acelulares (año 1981).

\section{¿Cuál es el proceso de fabricación de las vacunas celulares anti-pertussis?}

En su elaboración se cultiva $B$. pertussis en grandes fermentadores (contenedores) líquidos hasta alcanzar una concentración crítica, medida por turbidez, cuidando que la bacteria esté en un estado fenotípico llamado Fase I (fenotipo que implica la presencia de proteínas de adherencia a los epitelios, conocidas como aglutinógenos/ actualmente denominadas fimbrias y la presencia, con una frecuencia variable, de otros factores de virulencia). La potencia de la suspensión se valora mediante una prueba de inoculación en el cerebro de ratón lactante previamente inmunizado contra la bacteria (test de Kendrick). Todo este proceso encierra una variabilidad significativa (falta de consistencia entre lotes de un mismo fabricante y variaciones significativas entre fabricantes), la que se traducen en una eficacia y una seguridad inconvenientemente cambiantes.
Hospital Luis Calvo Mackenna, Santiago, Chile. Unidad de Infectología Servicio de Pediatría.

\section{El autor ha sido invitado por} Sanofi Pasteur, Pfizer y Novartis a congresos de la especialidad de infectología, a reuniones nacionales e internacionales sobre vacunación y a reuniones científicas sobre productos elaborados por estas casas farmacéuticas. Ha recibido honorarios como expositor o moderador en actividades académicas organizadas por estas tres casas farmacéuticas.

Recibido: 17de agosto de 2015 Aceptado: 14 de septiembre de 2015

Correspondencia a: José Cofré Guerra pepecofre@gmail.com 


\section{¿Cuál es el proceso de fabricación de las vacunas acelulares anti-pertussis?}

Es un procedimiento de purificación de los antígenos proteicos principalmente relacionados a virulencia y que estimulan respuesta inmune específica, a decir:

- Pertusinógeno (toxina pertussis-TP), factor de adherencia a epitelios y responsable de los principales efectos tóxicos sistémicos de la bacteria.

- Hemaglutinina filamentosa (HF), otro factor de adherencia a epitelios.

- Pertactina (PRN), una tercera adhesina.

- Fimbrias (FIM) 2 y 3, factores de adherencia antes denominados aglutinógenos, presentes en la bacteria en fase I de crecimiento.

Se han elaborado vacunas acelulares con un solo componente (TP detoxificada por manipulación genética), dos componentes $(\mathrm{TP}+\mathrm{HF})$, tres $(\mathrm{TP}+\mathrm{HF}+\mathrm{PRN})$ y cinco componentes (los 3 anteriores + FIM 2 y 3 ).

Este procedimiento logra descartar otras moléculas de la bacteria ligadas a efectos deletéreos como es el lipo-oligosacárido de su pared, asegurando una respuesta inmune dirigida a los antígenos que la conforman, y reduciendo los efectos adversos de la vacuna. La potencia de estas vacunas se determina mediante un test de desafío de inhalación de B. pertussis en ratones.

\section{¿Cuáles han sido los beneficios otorgados por las vacunas anti-pertussis celulares?}

Si comparamos la incidencia de la enfermedad antes y desde la introducción de estas vacunas, y su impacto en morbi-mortalidad, el beneficio ha sido indudable. Se cita repetidamente las lamentables experiencias de Japón, Suecia e Inglaterra que suspendieron la vacunación en los 70' por las aprehensiones arriba mencionadas, desencadenándose un alza sustancial en las tasas de ataque y fallecidos por coqueluche, hasta que re-introdujeron la vacunación en sus programas infantiles. Una buena vacuna celular ha alcanzado eficacia de $90 \%$ en estudios controlados, contra la enfermedad prolongada (tres semanas o más de tos) aunque otra vacuna celular alcanzó, en iguales condiciones de evaluación, una eficacia no superior a $30 \%$, confirmando la gran variabilidad de eficacia entre vacunas celulares de distintas procedencias.

\section{¿Cuál ha sido y es actualmente la procedencia de las vacunas celulares aplicadas en Chile?}

Históricamente, el Instituto de Salud Pública-ISP fabricó vacuna para el consumo interno hasta la década de los 90 , en que se detuvo la producción para iniciar la adquisición de vacuna DPT de fabricación en el exterior. Por largos años se empleó un producto elaborado por Pasteur Merieux (hoy Sanofi Pasteur) en Lyon, Francia. Posteriormente se introdujo la vacuna pentavalente de
GlaxoSmithKline. Hasta el año 2014, y desde el 2009, el Programa Nacional de Inmunizaciones (PNI) se abasteció de y utilizó el producto pentavalente Quinvaxem ${ }^{\circledR}$ de Novartis.

\section{¿Cuáles han sido los beneficios otorgados por las vacunas anti-pertussis acelulares?}

En primer lugar se ha demostrado su superior perfil de seguridad, escasamente causan reacciones adversas locales y se le han descrito muy esporádicos efectos sistémicos, incluyendo los efectos neurológicos. Por la naturaleza de su fabricación, que incluye una estricta valoración de su potencia, se ha alcanzado una buena consistencia entre lotes de fabricación asegurando una respuesta inmune relativamente estable. La eficacia en estudios de campo, para proteger contra enfermedad prolongada (tres semanas de tos o más) es cercana a $80 \%$, aunque varía entre productos. Se ha establecido como de óptima eficacia aquellas vacunas acelulares que contienen 3 a 5 componentes.

Un segundo beneficio es que su perfil de mayor seguridad ha permitido vacunar población sobre 7 años de edad, incluso adultos. Para estos efectos se han fabricado productos con una carga antigénica menor que la empleada en la vacunación del lactante y pre-escolar.

De alguna manera, la opinión pública ha depositado mayor confianza en las vacunas acelulares, reconociendo su mejor tolerancia, y las autoridades de salud han tendido a reemplazar los antiguos productos celulares por acelulares.

\section{¿Qué vacunas acelulares tenemos en el mercado nacional?}

Como vacunas hexavalentes (D/T/aP/Hib/HB/VPI) se expenden: Infanrixhexa ${ }^{\circledR}$ de GSK con 3 componentes de pertussis) y Hexaxim ${ }^{\circledR}$ de Sanofi Pasteur con 3 componentes de pertussis.

Como vacunas a usar en escolares, adolescentes y adultos, se comercializan: Boostrix ${ }^{\circledR}$ (componentes pertussis TP-HF y PRN) de GSK y Adacel ${ }^{\circledR}$ (componentes pertussis TP-HF-PRN y FIM 2-3) de Sanofi Pasteur, vacunas que contienen además toxoides tetánico y diftérico.

\section{¿Cuánto se han introducido las vacunas acelulares al mercado chileno?}

Para responder esta pregunta, debe precisarse que el PNI administra actualmente vacuna celular a los 2-4-6 y 18 meses de edad, en forma de vacuna pentavalente. En escolares se recomienda y utiliza vacuna acelular (en $1^{\circ}$ año básico y $8^{\circ}$ año básico). En el sistema privado existe la opción de adquirir vacunas acelulares para proteger al lactante.

Durante el año 2014, el Registro Nacional de Inmunizaciones (RNI), archivo computacional de las vacunas 
que se administran en el país, tanto por el sector público como por el sector privado, reconoce que 3,9\% de la población chilena en su cohorte a los seis meses de vida, ha recibido la vacuna acelular en su forma de vacuna hexavalente. Existen marcadas diferencias cuando esta información se desglosa por regiones administrativas. En un análisis de las regiones más populosas, en la Región de Antofagasta, este porcentaje alcanza al 9,8\%, en la Región Metropolitana (RM) es $6 \%$, en la Región del Bío-Bío 3,5\%, en La Araucanía 2,3\% y en la Región de Valparaíso $0,5 \%$. Dentro de la RM, hay comunas con porcentajes que superan el 50\% (Vitacura, Las Condes) y otras donde es $0 \%$.

\section{¿Cómo actúan una y otro tipo de vacuna?}

En un análisis profundo, los expertos han reconocido que se desconoce la manera exacta de cómo protegen las vacunas anti-pertussis contra una enfermedad que se asienta en la mucosa respiratoria, considerando que se trata de productos inactivados y administrados por vía parenteral. La respuesta inmune a la vacunación, analizada a continuación, no termina de contestar esta interrogante.

Respuesta inmune humoral (RIH). Si evaluamos la RIH (anticuerpos dirigidos contra los antígenos contenidos en la vacuna) en lactantes, las vacunas acelulares evocan un título mayor de anticuerpos contra los distintos antígenos. El significado clínico de ello es incierto. Por otra parte, la RIH a una dosis de refuerzo (booster) con vacuna acelular alcanza un mayor título de anticuerpos si el lactante recibió una primovacunación (dosis de los 2 meses o alguna otra más) con el producto celular. A la fecha, no existe acuerdo sobre qué anticuerpos o qué título de anticuerpos predice protección contra la enfermedad. Pese a ello, durante la evaluación de las vacunas acelulares, se realizó la medición de anticuerpos específicos contra cada uno de los antígenos incluidos en la vacuna con el objeto de medir inmunogenicidad de los productos.

Respuesta inmune celular (RIC). Modelos experimentales en animales han permitido entender que las vacunas celulares inducen una RIC que se asemeja a la respuesta celular observada en la infección natural y ante la enfermedad; la RIC a la infección natural y a la vacuna celular es de tipo Th1 y Th17, lo que se traduce en mayor celeridad y eficacia para erradicar la colonización del epitelio respiratorio por $B$. pertussis, comparado con las vacunas acelulares. Estas últimas estimulan una RIC predominantemente tipo Th2, comprobándose en el modelo animal una menor eficacia en eliminar la colonización del epitelio respiratorio en iguales condiciones experimentales.

Varios estudios de cohortes de lactantes han comprobado que la protección conferida por un esquema de va- cunación acelular es menor y que se pierde precozmente; en un trabajo esta protección cayó desde $75 \%$ a 12 meses plazo hasta $12 \%$ a cuatro años tras la vacunación.

\section{¿Beneficios conocidos de uno y otro tipo de vacuna anti-pertussis?}

Ya se ha mencionado el mérito de ambas vacunas en términos de disminuir la morbi-mortalidad por coqueluche en forma universal. Además, es inobjetable la mejor tolerancia de las vacunas acelulares. La confección de vacuna triple con baja carga antigénica de toxoide diftérico y de antígenos de $B$. pertussis -dTpa- (por motivos de seguridad) ha permitido aplicar y recomendar la vacunación anti-pertussis acelular más allá de los 7 años de edad, en adolescentes, adultos e, incluso últimamente, en mujeres en gestación.

\section{¿Cuáles son las limitaciones de ambas vacunas?}

Las vacunas celulares, por su perfil de efectos secundarios, no se recomienda emplearlas en personas sobre 7 años de edad. La protección que otorgan se estima en 6 a 10 años, al cabo de lo cual, el individuo vuelve a ser susceptible. Recientemente se está comprobando, en un modelo primate, que no evita la colonización nasofaríngea, si bien actúa eliminándola con mayor prontitud que lo que sucede en un animal control no vacunado.

Las vacunas acelulares protegen por un período menor que las celulares, según se desprende de observaciones epidemiológicas, plazo que ha sido estimado en dos a cuatro años. Adicionalmente, la diferente estimulación de RIC en comparación con la infección natural y con la vacunación celular, se correlaciona con una menor capacidad de eliminar el estado de portación nasofaríngea de $B$. pertussis.

En otras palabras, de esta última respuesta se desprende que las vacunas celulares inducen una respuesta inmune más eficiente sobre la mucosa respiratoria y más prolongada que las vacunas acelulares. Esta constatación pone en discusión la mejor forma de inmunizar al lactante: ¿vacunación celular con mayores efectos adversos pero mayor eficiencia o vacunación acelular mejor tolerada pero de menor eficiencia?

\section{¿Cuál sería la explicación de porqué re-emerge la coqueluche en el mundo?}

Hay varias líneas de investigación, cada cual ha demostrado ser cierta y, probablemente la explicación es que se trata de un fenómeno multicausal:

- B. pertussis ha evolucionado hacia una composición antigénica diferente haciendo menos protectoras las vacunas en uso. Varias naciones han aislado cepas de la bacteria carentes de PRN o que han variado en la composición de sus fimbrias. 
- B. pertussis ha incrementado su virulencia; se ha identificado cepas con mayor producción de TP.

- La introducción de vacuna acelular ha disminuido el tiempo de protección alcanzado por los programas de vacunación infantil.

- Como se explicó antes, ninguna de las vacunas evita la colonización nasofaríngea y por ende, tampoco la circulación de $B$. pertussis, incluso en población con alta cobertura de vacunas.

- Es indudable que existe mayor alerta clínica sobre esta enfermedad, aumenta la sospecha diagnóstica, se solicita un mayor número de exámenes confirmatorios y se notifica con mayor acuciosidad cada caso. La introducción de la reacción de polimerasa en cadena (RPC) ha aumentado la sensibilidad de la búsqueda, en particular en personas oligosintomáticas, en adolescentes y adultos $\mathrm{y}$, en portadores transitorios.

\section{¿De estos factores cuál (cuáles) es (son) el (los) responsable(s) de la situación epidemiológica chilena?}

Al momento actual, carecemos de cultivo sistemático de $B$. pertussis, lo que hace incontestable la hipótesis de evolución antigénica de la bacteriana o en su virulencia. Esto debe ser corregido.

Las coberturas de vacunación en lactantes chilenos, durante el año 2014 y en los inmediatamente anteriores, bordean el $90 \%$, porcentaje satisfactorio aunque no óptimo (debiera ser de 95\%).

El uso de vacuna acelular en nuestro país es marginal a diferencia de lo que sucede en otras naciones. Este factor no habrá sido mayormente determinante del resurgimiento de la enfermedad en nuestro medio.

Es posible que la falta de un refuerzo inmunitario natural (ausencia de enfermedad durante años) haya facilitado la acumulación de un reservorio adolescente y adulto suficiente para permitir el rebrote de la enfermedad. Sobre este punto, no estamos reconociendo la coqueluche en estas edades; adolecemos de una baja sospecha clínica y no disponemos con facilidad de la técnica diagnóstica indicada para su pesquisa: reacción de polimerasa en cadena.

Si no ha habido un refuerzo natural en población joven, los hijos nacen con escasa o nula protección transmitida por sus madres y así estamos viendo coqueluche fatal en los primeros meses de vida.

No olvidemos que existe una sobre-notificación de enfermedad en lactantes y pre-escolares, que falsea las tasas de ataque a estas edades, por el uso indiscriminado de los test de inmunofluorescencia directa o indirecta (escasamente específicos) para notificar un caso de coqueluche.

\section{Corolario}

En suma, pese a ser una enfermedad inmunoprevenible e hipotéticamente erradicable, y contra la cual se está intentando inmunizar más allá de la infancia, no se ha logrado controlar la coqueluche en el mundo. Las vacunas existentes, celulares y acelulares, no logran impedir la circulación de $B$. pertussis en poblaciones vacunadas y su corto efecto protector no han evitado el retorno a la susceptibilidad de escolares, adolescentes y adultos que ante fueron vacunados.

Es opinión de expertos que con los recursos disponibles, los países que utilizan vacuna celular en lactantes -es el caso de Chile- mantengan al menos la primera dosis ( 2 meses de edad) de vacuna celular (así su primera experiencia inmunológica con los antígenos de $B$. pertussis será tipo Th1/Th17) y de allí en adelante puedan utilizar vacunas hexavalentes, acudiendo a sus ventajas de seguridad y operacionales (menor número de inyecciones por sesión).

En el horizonte se ve surgir (ya en desarrollo en fase 1) vacunas con $B$. pertussis viva, de virulencia atenuada, para administración inhalatoria, lo que reproduce mejor la patogenia de la infección natural por B. pertussis, y con la esperanza de alcanzar con esta nueva estrategia no sólo el control sino que la eliminación de la enfermedad.

\section{Resumen}

El resurgimiento de la coqueluche en el mundo y en nuestro país ha puesto en tela de juicio la eficacia de las vacunas celulares y acelulares. Las razones de por qué la coqueluche no es controlada ni eliminada después de 70 años de implementación de la vacunación son diversas y probablemente multifactoriales. En este artículo, en base a preguntas y respuestas, se describen las bondades y limitaciones de tanto vacunas celulares como acelulares y queda sugerida una mejor forma de administrar ambas en la infancia. Es un hecho que la vacunación actualmente aplicada no elimina la circulación de Bordetella pertussis en la comunidad. Tal vez la introducción de vacunas con B. pertussis viva, inhalatoria, sea capaz de eliminar la enfermedad de la humanidad. 


\section{Lecturas recomendadas}

1.- Zhang L, Prietsch S O M, Axelson I, Halperin S. Acellular vaccines for preventing whooping cough in children. (Review). Cochrane Database Syst Rev 2014; CD 001498.

2.- Poolman J T. Pertussis vaccines. Expert Rev Vaccines 2014; 13 (9): 1067-9.

3.- Witt M, Arias L, Katz P H, Truong E T, Witt D J. Reduced risk of pertussis among persons ever vaccinated with whole-cell pertussis vaccine compared to recipient of acellular pertussis vaccines in a large US cohort. Clin Infect Dis 2013; 56 (9): 1248-54.

4.- Koepke R, Eickhoff J C, Ayele R A, Petit A B,
Schauer S L, Hopfensperger D J, et al. Estimating the effectiveness of TetanusDiphtheria-Acellular pertussis vaccine (Tdap) for preventing pertussis: evidence of rapidly waning immunity and difference in effectiveness by Tdap brand. Clin Infect Dis 2014; 210 (15 September): 942-53.

5.- Liko J, Robison S G, Cieslak P R. Priming with whole-cell versus acellular pertussis vaccine. N Engl J Med 2013 (February 7); 368 (6): 581-2.

6.- Warfel J M, Zimmerman L I, Merkel T J. Acellular pertussis vaccines protect against disease but fail to prevent infection in a nonhuman primate model. PNAS 2014 (January 14); 111: 787-92.

7.- Warfel J M, Edwards K M. Pertussis vaccines and the challenge of inducing durable immunity Curr Opinion Immunol 2015; 35: 48-54.

8.- Herzog C. Changing from whole-cell to acellular pertussis vaccines would trade superior tolerability to inferior protection. Expert Rev Vaccines 2015; 14 (8): 1065-72.

9.- Burns D L, Meade B D, Messionnier N E. Pertussis resurgence: Perspectives from the working group meeting on pertussis on the causes, possible paths forward and gaps in our knowledge. Clin Infect Dis 2014; 209 (S1): S32-5. 